\title{
Effects of incentive as a within- and between-subjects variable in risk-taking
}

RONALD C. PETERSEN and ARNOLD F. KANARICK, Systems and Research Center, Honeywell Inc., and B. R. HERGENHAHN, Hamline University, St. Paul, Minn.

Risk-taking behavior as a function of incentive condition, range of payoffs, and alternative to gambling was investigated in a mixed 2 by 3 by 3 factorial design. Thirty-six Ss were divided into three experimental groups depending on the incentive condition. Incentive was presented as both a within-and between-Ss variable, and range of payoffs and alternative to gambling were manipulated as within-Ss variables. It was hypothesized that incentive would have a greater effect on gambling behavior when presented as a within-Ss variable than as a between-Ss variable. The results did not support the hypothesis.

When each of two experimental groups experiences just one level of incentive, incentive is a between-Ss variable; when one experimental group experiences both levels of incentive, incentive is referred to as a within-Ss variable. Pubols $(1960)$, in his review of incentive experiments in animal learning, noted that when incentive was a between-Ss variable, it produced no performance differences; however, when it was a within-Ss variable, performance was directly related to the magnitude of incentive.

In human choice behavior, incentive has been used as a means of influencing risk-taking behavior. Myers, Fort, Katz, \& Suydam (1963) found in a probability matching task that Ss' risk-taking in a $10 \mathrm{c}$ group did not differ from Ss' behavior in a lc group. However, in an analogous task, Lipkin, Schnorr, Suydam, \& Myers (1965) found a significant difference between 10c and 1c risk conditions when all Ss experienced both levels of risk, i.e., when magnitude of incentive was a within-Ss variable.

Schnorr, Lipkin, \& Myers (1965) investigated the effects of incentive as a within-Ss variable and as a between-Ss variable in a probability learning task and found differential effects. The Ss' behavior did not vary when Ss were exposed to only one level of risk, but did vary when Ss were exposed to both levels of risk. Katz (1962) used incentive vs no incentive as a between-Ss variable and found no significant effect on risk-taking behavior.

The literature indicates that the effects of incentive may vary with the manner in which the incentive is presented, i.e., as a between- or within-Ss variable. To further investigate this relationship and to determine a possible explanation for the failure of Katz to find a significant incentive effect, the present experiment was designed to explore the effects of incentive presented in these two ways on a choice behavior involving gambling. It was hypothesized that incentive would have a greater effect on gambling behavior when manipulated as a within-Ss variable than as a between-Ss variable. In addition, range of payoff and alternative to gambling were manipulated as within-Ss variables.

\section{SUBJECTS}

Thirty-six introductory psychology students at Hamline University were randomly assigned to three experimental groups having 12 Ss each. The first group (Incentive or I) gambled for poker chips worth $3 \mathrm{c}$ apiece, and the second group (No Incentive or NI) gambled only for poker chips (0c). The third group (Partial Incentive or PI) gambled for poker chips worth $3 \mathrm{c}$ each on half the trials and gambled for the chips themselves $(0 \mathrm{c})$ on the other half of the trials.

\section{MATERIALS}

One deck of $903 \times 5$ in. white cards served as the deck of the known outcomes. Forty-five of the cards were marked +1 , and 45 were marked -1 . Three other decks of 30 cards each were prepared and served as the unknown outcome decks. The narrow range deck (N) had an equal number of cards marked from +2 to +6 and from -2 to -6 . The medium range deck $(M)$ was prepared by adding 10 to those cards marked +2 to +6 in the first deck and adding -10 to those cards marked -2 to -6 , thus yielding ranges of +12 to +16 and -12 to -16 . The wide range deck (W) was prepared in a similar manner by adding a +20 and a -20 to the appropriate cards in the first deck. The Ss were given poker chips with which to gamble.

\section{PROCEDURE}

The Ss' task was to turn over the top card of the known payoff deck and examine its value. They could decide to either accept this outcome $(+1$ or -1$)$ or gamble on the outcome of one of the decks of unknown payoff. All that Ss knew about the second deck was that it contained plus and minus values of greater magnitude than one. If they decided to gamble, they were compelled to accept this outcome. If they chose not to gamble, the top card of the second deck was turned over showing what the outcome would have been had they decided to gamble. The Ss were told to win as many chips as possible.

A mixed 2 by 3 by 3 factorial design (Myers, 1966, pp. 202-203) was used with the within-Ss variables being alternative to gambling $(+1,-1)$ and range of payoffs of unknown deck (narrow, medium, wide), and the between-Ss variable being the incentive condition (no incentive, incentive, partial incentive). Each $S$ was given 90 trials, 30 at each level of range, with the order of presentation counterbalanced. In the PI group, the order of presentation of the 45 incentive trials and the 45 no incentive trials was counterbalanced over Ss, with the levels of range being counterbalanced within each incentive condition.

Each $S$ began the experiment with 200 chips and was paid $\$ 2.00$ for his services. Those $S$ s in the incentive condition were told that each chip was worth $3 c$, and therefore, their initial stake was $\$ 6.00$. They were also informed that, at the conclusion of the experiment, their chips would be totalled, and they could keep any amount that they had won over their initial stake. Similarly, if their final total was less than the initial $\$ 6.00$, this difference would be subtracted from their $\$ 2.00$ pay. The Ss were told that they would not be charged more than $\$ 2.00$, so that they could not end up owing $E$ any money.

\section{RESULTS AND DISCUSSION}

The raw scores were proportions of choices to gamble given a +1 or -1 outcome on the first deck. For example, if $S$ had decided to gamble on $9 / 15$ of the -1 outcomes and on $5 / 15$ of the +1 outcomes for the incentive, narrow range condition, then his raw scores would be .600 and .333 , respectively. Table 1 shows the mean proportions of choices to gamble corresponding to the various experimental conditions.

An analysis of variance was performed on the arcsine transforms of the proportions (Myers, 1966, p. 64) in the mixed 2 by 3 by 3 factorial design. Significantly more gambling took place on the -1 outcomes than on the +1 outcomes across all range and incentive conditions $(F=47.63, \mathrm{df}=1 / 33, \mathrm{p}<.001)$. The incentive variable failed to produce a significant difference in gambling behavior when presented as a between-Ss variable, and similarly no significant performance differences were found between the PI group and either of the $I$ or the NI groups $(F=.71, \mathrm{df}=2 / 33$, $p>.10)$. Range also had no significant effect $(F=1.93, \mathrm{df}=2 / 66$, $p>.10)$, nor were any of the interactions significant.

To examine the possibility that a difference between the incentive and no incentive conditions within the PI group was

Table 1

Mean Proportion of Gambling Responses

\begin{tabular}{|c|c|c|c|c|c|c|c|c|}
\hline \multirow[b]{3}{*}{ Range } & \multirow{2}{*}{\multicolumn{2}{|c|}{ Group I }} & \multirow{2}{*}{\multicolumn{2}{|c|}{ Group NI }} & \multicolumn{4}{|c|}{ Group PI } \\
\hline & & & & & \multicolumn{2}{|c|}{ I } & \multicolumn{2}{|c|}{ NI } \\
\hline & -1 & +1 & -1 & +1 & -1 & +1 & -1 & +1 \\
\hline Narrow & .693 & .465 & .661 & .397 & .735 & .383 & .831 & .513 \\
\hline Medium & .661 & .428 & .622 & .333 & .661 & .356 & .673 & .481 \\
\hline Wide & .554 & .411 & .676 & .405 & .687 & .530 & .680 & .454 \\
\hline
\end{tabular}


obscured in the aforementioned analysis of variance, two additional analyses of variance were performed. One analysis was run using only the $I$ and the NI groups, and the other analysis included only the data of the PI group. As expected, significant value effects were found in both analyses $(\mathrm{F}=27.45, \mathrm{df}=1 / 22$, $\mathrm{p}<.001 ; \mathrm{F}=23.24, \mathrm{df}=1 / 11, \mathrm{p}<.001$, respecitvely); however, no incentive effects nor range effects were found in either case. Furthermore, none of the interactions were significant.

The finding that Ss gambled significantly more when presented with a -1 outcome than with a +1 outcome is consistent with previous studies (Katz, 1962; Myers \& Katz, 1962; Myers \& Sadler, 1960). The lack of a significant range or incentive main effect is also consistent with Katz (1962).

The hypothesis that incentive would have a greater effect on gambling behavior when manipulated as a within-Ss variable than as a between-Ss variable was not supported. This may have been due, in part, to the Ss' inability to reach asymptotic behavior because of an insufficient number of trials, especially in the PI group. Also, it is possible that the range of values for the no incentive and incentive conditions $(0 \mathrm{c}$ and $3 \mathrm{c}$ ) may not have been large enough to allow $\mathrm{Ss}$ to perceive a real distinction between incentive and no incentive.

\section{REFERENCES}

KATZ, L. Monetary incentive and range of payoffs as determiners of risk taking. Journal of Experimental Psychology, 1962, 64, 541.544.

LIPKIN, S. G., SCHNORR, J. A., SUYDAM, M. M., \& MYERS, J. L. Effects of risk as a within-S variable in probability learning. Psychonomic Science, 1965, 2, 145-146.

MYERS, J. L. Fundamentals of experimental design. Boston: Allyn and Bacon, 1966.

MYERS, J. L., FORT, J. G., KATZ, L., \& SUYDAM, M. M. Differential monetary gains and losses and event probability in a two-choice situation. Journal of Experimental Psychology, 1963, 66, 521-522.

MYERS, J. L., \& KATZ, L. Range of payoffs and feedback in risktaking. Psychological Reports, 1962, 10, 483-486.

MYERS, J. L., \& SADLER, E. Effects of range of payoffs as a variable in risktaking. Journal of Experimental Psychology, 1960, 60, 306-309.

PUBOLS, B. Incentive magnitude, learning, and performance in animals. Psychological Bulletin, 1960, 57, 89-115.

SCHNORR, J. A., LIPKIN, S. G., \& MYERS, J. L. Level of risk in probability learning: Within- and between-Ss design. Journal of Experimental Psychology, 1966, 72, 497-500. 